\title{
Erratum to: CT and MRI in Ovarian Carcinoma
}

Rosemarie Forstner

Erratum to: Med Radiol Diagn Imaging

DOI 10.1007/174_2017_17

Inadvertently, the chapter was published online with a co-author - Carolyn M. Zelop, who has not contributed to this chapter. The co-author name has been deleted now from the original version.

The updated online version for this chapter can be found under DOI 10.1007/174_2017_17

R. Forstner $(\bowtie)$

Salzburger Landeskliniken, Paracelsus Medical University, Müllner Hauptstr. 48, Salzburg 5020,

Austria

e-mail: R.Forstner@salk.at 